\title{
The TEAM instrument for measuring emergency team performance: validation of the Swedish version at two emergency departments
}

\author{
Klas Karlgren ${ }^{1,2,3^{*}} \mathbb{0}$, Anders Dahlström ${ }^{1,4}$, Anderz Birkestam ${ }^{5}$, Annelie Drevstam Norling ${ }^{5}$, Gustav Forss ${ }^{5}$, \\ Mikael Andersson Franko ${ }^{6}$, Simon Cooper ${ }^{7}$, Thomas Leijon ${ }^{8}$ and Charlotta Paulsson ${ }^{8}$
}

\begin{abstract}
Background: The Team Emergency Assessment Measure (TEAM) questionnaire is designed for rating the nontechnical performance of emergency medical teams during emergencies, e.g., resuscitation or trauma management. Originally developed in Australia it has today been translated and validated into eleven languages, but a Swedish version is lacking. The aim was therefore to cross-culturally translate and evaluate the reliability and validity of the TEAM questionnaire in a Swedish health care setting.
\end{abstract}

Methods: The instrument was forward and backward translated and adapted into a Swedish context according to established guidelines for cross-cultural adaptation of survey-based measures. The translated version was tested through 78 pairwise assessments of 39 high-priority codes at the emergency departments of two major hospitals. The raters observed the teams at work in real time and filled in the questionnaires immediately afterwards independently of each other. Psychometric properties of the instrument were evaluated.

Results: The original instrument was translated by pairs of translators independently of each other and reviewed by an expert committee of researchers, nurses and physicians from different specialties, a linguist and one of the original developers of the tool. A few adaptations were needed for the Swedish context. A principal component factor analysis confirmed a single 'teamwork' construct in line with the original instrument. The Swedish version showed excellent reliability with a Cronbach's alpha of 0.955 and a mean inter-item correlation of 0.691 . The mean item-scale correlation of 0.82 indicated high internal consistency reliability. Inter-rater reliability was measured by intraclass correlation and was 0.74 for the global score indicating good reliability. Individual items ranged between 0.52 and 0.88 . No floor effects but ceiling effects were noted. Finally, teams displaying clear closed-loop communication had higher TEAM scores than teams with less clear communication.

Conclusions: Real time observations of authentic, high priority cases at two emergency departments show that the Swedish version of the TEAM instrument has good psychometric properties for evaluating team performance. The TEAM instrument is thus a welcome tool for assessing non-technical skills of emergency medical teams.

*Correspondence: klas.karlgren@ki.se

1 Department of Research, Education, Development and Innovation

Södersjukhuset, 11883 Stockholm, Sweden

Full list of author information is available at the end of the article permits use, sharing, adaptation, distribution and reproduction in any medium or format, as long as you give appropriate credit to the original author(s) and the source, provide a link to the Creative Commons licence, and indicate if changes were made. The images or other third party material in this article are included in the article's Creative Commons licence, unless indicated otherwise in a credit line to the material. If material is not included in the article's Creative Commons licence and your intended use is not permitted by statutory regulation or exceeds the permitted use, you will need to obtain permission directly from the copyright holder. To view a copy of this licence, visit http://creativecommons.org/licenses/by/4.0/. The Creative Commons Public Domain Dedication waiver (http://creativeco mmons.org/publicdomain/zero/1.0/) applies to the data made available in this article, unless otherwise stated in a credit line to the data. 
Keywords: Teamwork, Communication, Assessment, Instrument, Validation, Measure, Non-technical skills, Observational research, Emergency

\section{Background}

Effective interprofessional teamwork and team communication are crucial in the delivery of safe, high-quality health care [1-3], with adverse outcomes often ascribed to inadequate leadership, communication, teamwork, decision-making and task distribution [4-6]. Team collaboration and communication, especially in critical situations, may be challenged by factors such as heavy workloads requiring multi-tasking and dealing with numerous patients, hasty decisions based on incomplete information, dynamic teams with multiple handovers and frequent staff member substitutions, lack of resources, interruptions, and background noise $[1,2,7]$.

To manage complex tasks, teams have to be able to exchange information, coordinate efforts and adapt to changing situational factors. Teamwork has been described as the interrelated team member behaviors, thoughts, and feelings needed for the team to function as a unit relying on mechanisms such as closed-loop communication, shared understanding, and mutual trust $[8,9]$. A current discussion, not only in health care, is how education and training can better prepare for the requirements of workplaces [10]. Continual efforts have been made to define and assess individual and collective competence relating to collaboration, teamwork and interprofessional interaction [11, 12]. Despite having a comparatively strong tradition of emphasizing teamwork in health care in Scandinavia, the need for a greater focus on teamwork has been called for both in civilian health care [13] and military medicine [14]. The Swedish Society of Medicine and the Swedish Society of Nursing have jointly argued for more team training in health care education [15]. Besides more team training, physicians have argued for the need to investigate how non-technical skills develop and how team training contributes to clinical work [16]. A recent review notes that team research has received greater attention in the area of health care over the last decade but has nevertheless resulted in a small number of research studies [3]. The review concludes that this may relate to the difficulties in quantifying teamwork.

Standardized observation in the emergency department is one method that may be helpful in identifying threats to safety and opportunities for improvement [17]. Observations can provide insights about teamwork on a level that is unmatched by other methods; interview or focus group participants are for example unlikely to remember or be able to describe with precision the details that observers can detect [18]. However, learning to observe and analyze the performance of medical teams is not a trivial task and may not develop with experience alone. While experienced simulation educators may display skills in analyzing team performance [19], such skills may be the result of years of competence development [20].

The complexities of team performance pose a challenge to measuring team performance [21] and a challenge for research is to develop and validate instruments for team performance assessment both for the design of team training efforts as well as effective clinical work [22]. A number of assessment tools have been developed for measuring the teamwork performance in crisis situations addressing various aspects of non-technical skills such as leadership, communication, coordination, situation awareness, planning, re-evaluation, and task and resource management [23-26]. Tools have most often been assessed within emergency medicine teams followed by obstetrical and pediatric teams and in most cases the measurement properties of the tools have been assessed based on simulated cases [25]. Many of the available assessment tools overlap regarding the skills that are assessed and the need for more psychometric evidence of the properties of assessment tools has been argued for [24]. While the choice of instrument will depend on many parameters such as the context and goal of the assessment, a recent review of assessment measures singled out the Team Emergency Assessment Measure (TEAM) as the most promising tool as it has shown robust evidence of its measurement properties [25].

TEAM is an observational tool for the assessment of resuscitation and emergency team performance which addresses three overall categories of teamwork-leadership, teamwork and task management-covering leadership control; communication; co-operation and coordination; team climate; adaptability; situation awareness; prioritization; and clinical standards. In addition, one item is a global rating measuring the overall 'gut reaction' to performance. The original English version of the instrument has been translated into 11 languages including Chinese, Finnish [27], French [28], German [29], Hebrew, Italian, Persian and Portuguese. ${ }^{1}$

A Swedish version of the TEAM instrument has however been lacking. The aim of this study was therefore to cross-culturally translate and evaluate the reliability and validity of the Team Emergency Assessment Measure (TEAM) questionnaire in a Swedish health care setting.

\footnotetext{
${ }^{1}$ http://medicalemergencyteam.com/
} 


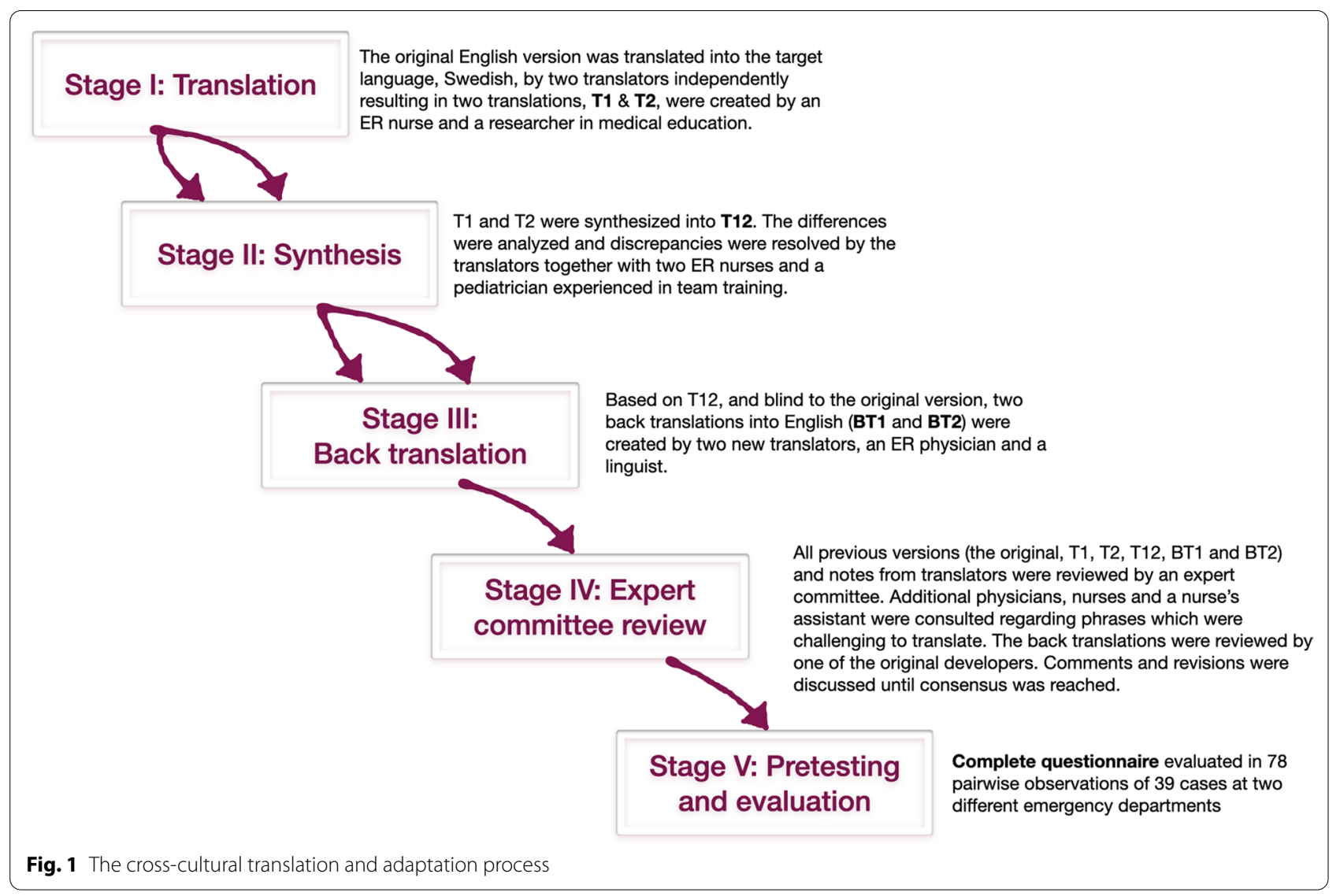

\section{Methods}

The original TEAM instrument was translated into Swedish following the methods suggested for cross-culturally translating an instrument and adapting it to another cultural context [30-32]. Translation of the instrument is considered the first step, but different models have been proposed for taking into account cultural, idiomatic, conceptual, experiential, and contextual aspects to minimize risks for biases and detect ambiguous wordings [31, 33]. Instruments which are not accurately adapted risk generating inconsistent and unreliable data [31]. The suggested multi-step procedures for translating and adapting instruments need to balance the needs for ensuring that a translated instrument on the one hand reflects the content of the original version and at the same time makes sense in the target language in a new context.

First two translators independently of each other translated the original instrument into the target language, Swedish (see Fig. 1). One of the forward translations (T1) was completed by an experienced nurse working at a large emergency room and the other by a researcher in medical education (T2). Both translators were knowledgeable of the topic. To synthesize the results, two nurse specialists in emergency nursing and a pediatrician experienced in team training were invited to discuss the differences between translations. Issues were resolved through consensus and a common translation (T-12) was produced.

Using the T-12 version of the questionnaire and blinded to the original version, two new translators translated back from Swedish into English enabling comparisons of the back-translations (BT1 and BT2) to the original version. One of the back-translators was a Swedish emergency physician and professor of emergency medicine with English as her mother tongue while the other was a Swedish professor and linguist with extensive work experience from the United States. The two translators worked independently of each other and were not informed of the concepts explored to avoid information bias and to elicit unexpected meanings of the items [30, 33].

The different translations of each item and the translators' notes were color-coded and compiled in one document for easier comparison of the different versions. An expert committee consisting of the translators and the two additional ER nurses and the pediatrician reviewed 
any discrepancies to create a new synthesis. As certain words and phrases were challenging to translate, the committee consulted another senior pediatrician and simulation educator, an intensive care nurse, a pediatric nurse, two pre-hospital care nurses, a surgeon, a nurse's assistant, and a nurse specialist in emergency nursing responsible for the hospital's CPR training. Involving the original instrument's authors has been recommended [31] and the back-translations were therefore reviewed by Professor Simon Cooper, the lead developer of the original English instrument. New comments were discussed until reaching consensus and finally resulting in a Swedish version (Fig. 2). The Swedish translation was then tested and evaluated as described below.

\section{Cases and participants}

Pairwise observers made 78 real time observations of 39 cases at the emergency departments in two hospitals in Stockholm: 13 cases at the Saint Göran Hospital and 26 cases at the Södersjukhuset hospital. Recommendations about sample numbers required for validating an instrument vary to a high degree and an absolute rule does not exist [32, 34]. A previous study validating a French translation of the same instrument using video-recordings of cardiac arrest simulations served as inspiration [28]. However, as this study investigated authentic cases without being able to predict the kind of patient cases, which weekday or time of the day that they occurred, nor who would be members and leaders of the teams the number of observed cases was increased. The hospitals that were included are both major hospitals in Stockholm and the Södersjukhuset hospital has one of the largest emergency departments in Scandinavia. The observed cases were the most highly prioritized emergency codes (red, prio-1) involving life-threatening injuries and conditions. The cases included conditions and symptoms such as: arrhythmia, abdominal pains, allergic reactions, cardiac arrest, chest pains, dyspnea, exacerbations of chronic obstructive pulmonary disease, injuries from falling and traffic accidents, intoxications, loss of consciousness, presyncope, sepsis, and stroke. The patients typically arrived by ambulance but may also have checked in at the receptionist's desk or been transferred from other departments within the hospital. These patients were then managed by an emergency team. The observed teams had between four to seventeen members $($ mean $=7$; median $=6$ ) with a typical team consisting of one-two physicians, two nurses, one nurse's assistant and a medical student. Often an anesthesiologist and an anesthesia nurse were also present and occasionally a surgeon, cardiologist or other specialist as well as more nurses including stroke nurses.

\section{Data collection}

The observers were experienced nurses and physicians employed at the two emergency departments and had practiced using the questionnaire on video-recordings of simulated cases equivalent to the authentic ones. The observers were allowed time off from their ordinary work tasks and they were thus not expected to be involved in regular work when rating. One pair of observers rated all cases at the Saint Göran hospital. At the Södersjukhuset hospital pairwise observations were performed with one person conducting all observations together with one other person from a pool of four observers. Altogether 78 observations were conducted. The Swedish version of the TEAM questionnaire was filled in independently of each other immediately after having observed the cases. The durations of the observations ranged between 7 and $56 \min ($ mean $=25 \min 27 \mathrm{~s}$; median $=22 \min 25 \mathrm{~s}$ ). Observations were conducted during different weekdays and different times of the day including nighttime to avoid biases related to time and day. The data collection was initiated in 2015 and completed in 2020.

\section{Data analysis}

The following metrics were analyzed: (1) A principal component factor analysis; (2) internal consistency among items was analyzed by calculating Cronbach's alpha coefficients; (3) internal consistency was also analyzed by investigating inter-item correlation; (4) item-scale correlation; (5) inter-rater reliability of the pairwise observers' assessments using Intra Class Correlation (ICC); (6) floor and ceiling effects; and finally, (7) a Kruskal-Wallis test was used to investigate if the quality of the teams' communication was reflected in the results of the TEAM instrument. Data from a study performed at the Södersjukhuset hospital which had a focus on closed-loop communication and other nontechnical skills were used for comparison; the same team situations were assessed regarding the quality of communication using a software designed for live observations (Obansys). Raters used a predefined observation schedule to count each occurrence of a (1) clear, directed order (defined as spoken out load for the entire team to hear and clearly addressed to another team member by name), (2) unclear order, (3) clear confirmation (clearly responding to an order by repeating it), and (4) unclear or missing confirmation. Counting was done by clicking on corresponding buttons in the Obansys app on an iPad. The results of these counts were not available for the observers, but the measures were later used to categorize the quality of the communications as being either low, intermediate or high based on an overall assessment of the four measures. The quality of communication was 


\section{Team Emergency Assessment Measure (7E, AM)}

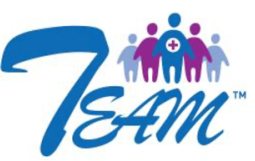

\section{[Swedish] Ett instrument för bedömning av teamarbete i akutsjukvård}

\begin{tabular}{|c|c|c|c|c|}
\hline \multicolumn{5}{|c|}{ Introduktion } \\
\hline \multicolumn{5}{|c|}{$\begin{array}{l}\text { Detta frågeformulär är avsett för bedömning av icke-tekniska färdigheter hos akutteam (tex traumateam eller } \\
\text { återupplivningsteam). Formuläret är utformat som ett observationsverktyg för valida, reliabla och genomförbara } \\
\text { bedömningar. Det är tänkt att fyllas i av kliniker med sakkunskap för att tillförlitlligt kunna bedöma och återkoppla om } \\
\text { ledarskap, teamarbete, situationsmedvetenhet och hantering av arbetsuppgifter. I de fall det är tillämpligt åtföljs } \\
\text { påståendena av förtydligande exempel och vägledning. Bedöm påståendena nedan med följande skala: }\end{array}$} \\
\hline Aldrig/nästan aldrig & Sällan & Väger jämnt & Ofta & Alltid/nästan alltid \\
\hline 0 & 1 & 2 & 3 & 4 \\
\hline
\end{tabular}

\section{Uppgifter om teamet}

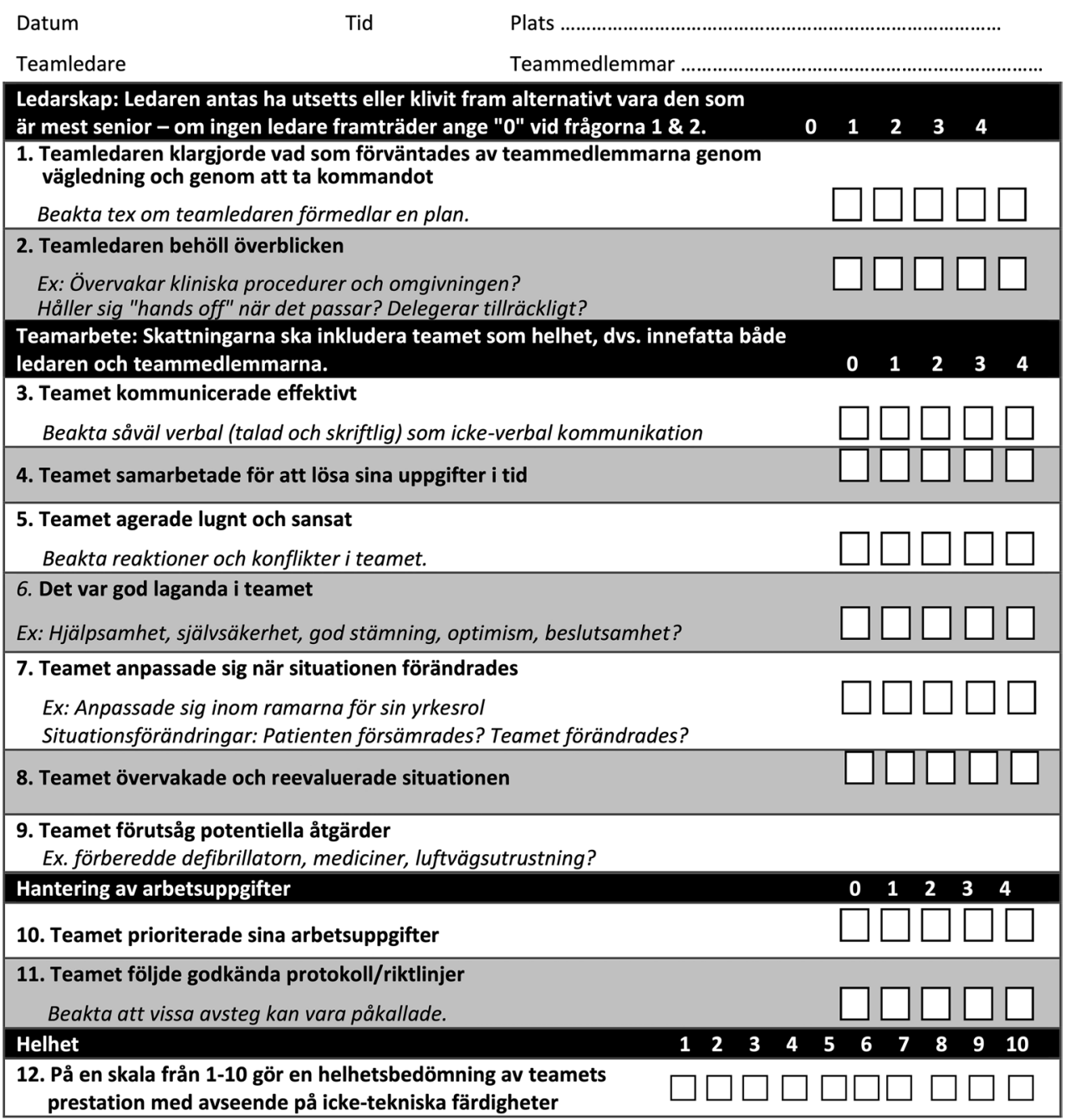

Kommentarer:

Fig. 2 The Swedish version of the Team Emergency Assessment Measure (TEAM) questionnaire. The instrument and instructions for its use can be found here: http://medicalemergencyteam.com 
interpreted as high if at least three of the four measures were above the medians, or, if two scores were above the medians and none of the other two measures were below median scores. Low quality was rated in the opposite fashion. All other cases-which thus did not consistently show low or high scores-were considered intermediate. $P$ values of $<0.05$ were considered statistically significant.

We hypothesized that TEAM scores would differ according to the quality of communication with cases of high quality receiving higher scores.

Analyses were performed using R (v3.6.0, 2021, Vienna, Austria) and Microsoft Excel v16.46 for Mac.

\section{Results}

\section{Cross-cultural translation and adaptation}

While the pairs of translators occasionally suggested different wordings and phrases a consensus was reached on a final translation that followed the original version but which was adapted to the Swedish health care context. Finding a satisfactory translation for one phrase was however challenging. A literal translation of the first item about the team leader (The team leader let the team know what was expected of them through direction and command) was not applicable in the Swedish setting. The phrase"through command" was considered to have an authoritarian or militaristic connotation and being interpreted negatively in a civilian health care setting and as a marker of unsound leadership, in contrast to what was intended by the original item.

The expert committee therefore consulted numerous physicians and nurses within different specialties as well as experienced simulation and CPR educators to find a better wording. Almost 20 different Swedish translations were tried ('befallningar,' 'order,' 'kommandon', 'uppmaningar' etc.) but the conclusion was that the difficulty was less about identifying the perfect literal translation but more about cultural differences regarding leadership. This tension between a literal translation and a cultural bias was resolved by consulting experienced simulation educators about how they teach team leaders with regard to leadership processes in relation to such items as "let the team know what is expected of them". A wide-spread team-training and simulation approach in Sweden-the CEPS model (Concept for Patient Simulation)-emphasizes that team leaders should convey a plan to the team rather than to simply give orders. By making the team aware of the team leader's plan, team members have a better chance of understanding the team leader's instructions and what is expected of them. Taking this into account, the final solution to the translation challenge was to use a literal translation but also to add a prompt after the item relating to the Swedish practice ("Consider whether the team leader conveys a plan"). This solution thus follows the original version but lessens the risk of misunderstanding the item as something negative. The original author (SC) of the TEAM instrument suggested seven changes. Most of these concerned inaccuracies and vagueness in the back-translations. Minor modifications were made to the title and background information but changes to the actual items were not needed.

\section{Psychometric results}

A principal component factor analysis was conducted and identified one component explaining $73.6 \%$ of the variance which is in line with the original instrument that was shown to measure a single factor, 'teamwork' [35].

Internal consistency or scale reliability, i.e., the extent to which all the items in a test measure the same concept, was measured by calculating Cronbach's alpha and was 0.955 for the entire Swedish TEAM instrument thus confirming excellent internal consistency. To further investigate internal consistency inter-item correlations were also calculated. The extent to which scores on one item were related to scores on all the other items in the instrument were examined showing a range of $0.43-0.86$ and a mean correlation of 0.691 which is considered high. In comparison, the inter-item-correlations of the original instrument were $0.58-1$ and of the French translation $0.47-0.85$ [28].

An item-scale (item-total) analysis was performed to check if any item was inconsistent with the averaged behavior of the others. Each item was correlated with the total scale score (based on all items except nr 12) corrected for overlap, i.e., the particular item taken out of the total score. The item-scale correlations ranged between 0.70 and 0.89 with a mean of 0.82 which is considered high and indicating that items measure the same general construct and thus implying a high internal consistency reliability, see Table 1.

Inter-rater reliability was measured by calculating intraclass correlation (ICC) of the following type: oneway random effects, absolute agreement, single rater measurement. The ICC measurements of the individual items ranged between 0.52 and 0.88 . According to common guidelines [36], less than 0.40 is considered poor, 0.40 and 0.59 fair, 0.60 and 0.74 good and 0.75 and 1.00 excellent. The measurements thus range between fair and excellent and most items were either good or excellent. Two items (8 and 9) resulted in an ICC value of 0.52 and another item (4) resulted in 0.59. As a comparison, the original instrument showed an ICC range of 0.59-0.88.

Inter-rater reliability for the global TEAM score (a sum of the scores of all items) was also calculated (two-way, 
Table 1 Item-scale correlations, inter-rater reliabilities (IRR) measured using intraclass correlation (ICC), \% of lowest and highest values to indicate floor and ceiling effects, and $p$ values of the Kruskal-Wallis test

\begin{tabular}{|c|c|c|c|c|c|c|}
\hline Item & $\begin{array}{l}\text { Cronbach's } \\
\text { alpha }\end{array}$ & $\begin{array}{l}\text { Item-scale } \\
\text { correlation }\end{array}$ & IRR (ICC) & Floor (\%) & Ceiling (\%) & $\begin{array}{l}\text { Kruskal- } \\
\text { Wallis } \\
\text { test }\end{array}$ \\
\hline $\begin{array}{l}\text { 1. The team leader let the team know what was expected of them through } \\
\text { direction and command }\end{array}$ & 0.79 & 0.77 & 0.88 & 15.4 & 17.9 & $0.048^{*}$ \\
\hline $\begin{array}{l}\text { 2. The team leader maintained a global perspective } \\
\text { Prompts: monitoring clinical procedures and the environment? Remaining } \\
\text { 'hands off' as applicable? Appropriate delegation }\end{array}$ & 0.86 & 0.83 & 0.67 & 2.6 & 41.0 & $0.035^{*}$ \\
\hline $\begin{array}{l}\text { 3. The team communicated effectively } \\
\text { Prompts: verbal, non-verbal and written forms of communication? }\end{array}$ & 0.87 & 0.89 & 0.77 & 3.8 & 15.4 & $0.017^{*}$ \\
\hline 4. The team worked together to complete the tasks in a timely manner & 0.87 & 0.86 & 0.59 & 1.3 & 33.3 & $0.037^{*}$ \\
\hline $\begin{array}{l}\text { 5. The team acted with composure and control } \\
\text { Prompts: applicable emotions? Conflict management issues? }\end{array}$ & 0.84 & 0.76 & 0.62 & 0.0 & 70.5 & 0.089 \\
\hline $\begin{array}{l}\text { 6. The team morale was positive } \\
\text { Prompts: appropriate support, confidence, spirit, optimism, determination? }\end{array}$ & 0.86 & 0.83 & 0.69 & 1.3 & 55.1 & 0.088 \\
\hline $\begin{array}{l}\text { 7. The team adapted to changing situations } \\
\text { Prompts: adaptation within the roles of their profession? } \\
\text { Situation changes: patient deterioration? Team changes? }\end{array}$ & 0.80 & 0.70 & 0.76 & 2.4 & 22.0 & 0.349 \\
\hline 8. The team monitored and reassessed the situation & 0.85 & 0.83 & 0.52 & 3.9 & 29.9 & 0.284 \\
\hline $\begin{array}{l}\text { 9. The team anticipated potential actions } \\
\text { Prompts: preparation of defibrillator, drugs, airway equipment? }\end{array}$ & 0.86 & 0.86 & 0.52 & 6.5 & 31.2 & 0.081 \\
\hline 10. The team prioritised tasks & 0.81 & 0.80 & 0.60 & 7.7 & 28.2 & $0.018^{*}$ \\
\hline $\begin{array}{l}\text { 11. The team followed approved standards and guidelines } \\
\text { Prompt: some deviation may be appropriate? }\end{array}$ & 0.93 & 0.89 & 0.60 & 6.5 & 31.2 & $0.022^{*}$ \\
\hline 12. On a scale of 1-10 give your global rating of the team's performance & 0.94 & - & 0.83 & 1.3 & 3.9 & $0.012^{*}$ \\
\hline
\end{tabular}

$P$ values of $<0.05$ are marked with $a^{*}$. The items are presented in English for readability

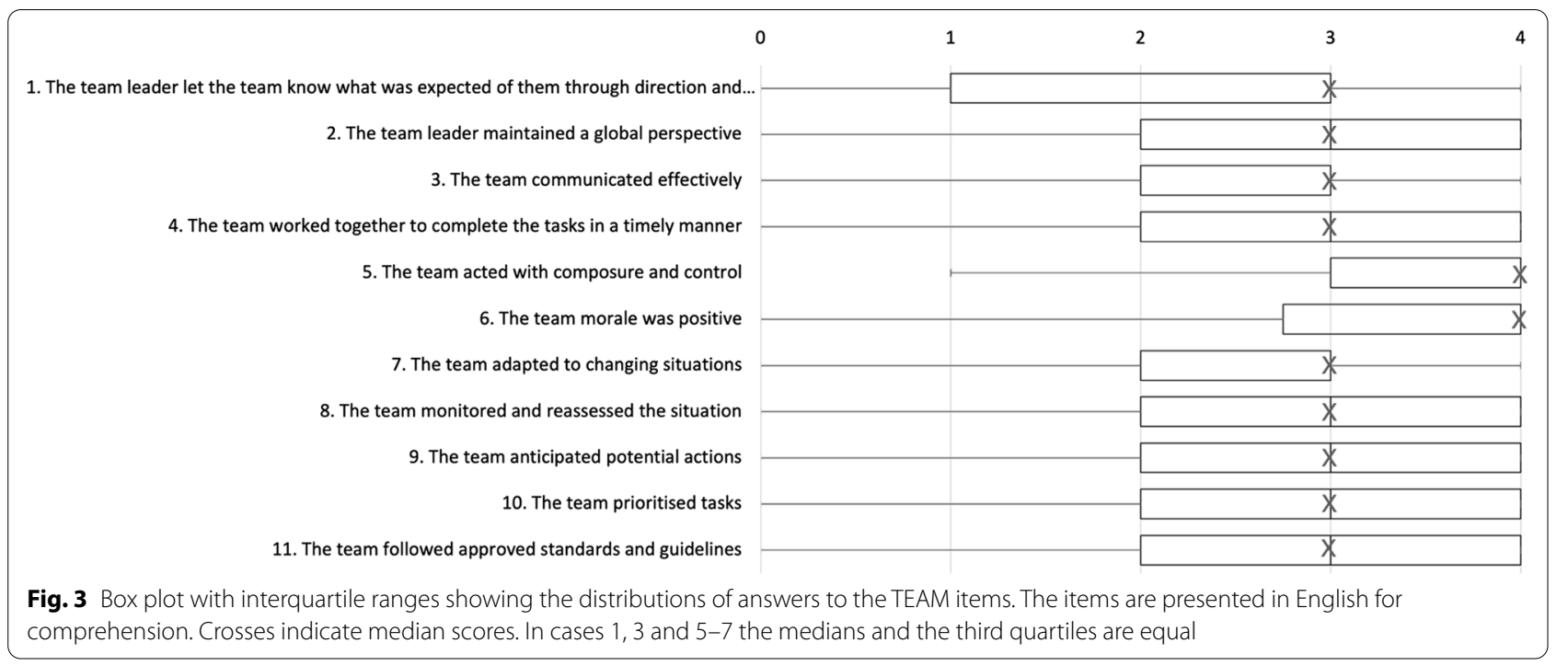

random effects) showing 0.74 and thus indicating good reliability.

All scale values of all items were used except for item 5 which never received the lowest score, '0', see Fig. 3. Floor or ceiling effects are considered to be present if more than $15 \%$ of cases achieved the lowest or highest possible score. The distribution of the results showed no floor effects except for item 1 , see Table 1 . However, ceiling effects were noted for all items except for item 12.

A Kruskal-Wallis test (one-way ANOVA on ranks) was performed to compare the TEAM results to the quality of communication in the teams. Figure 4 shows 


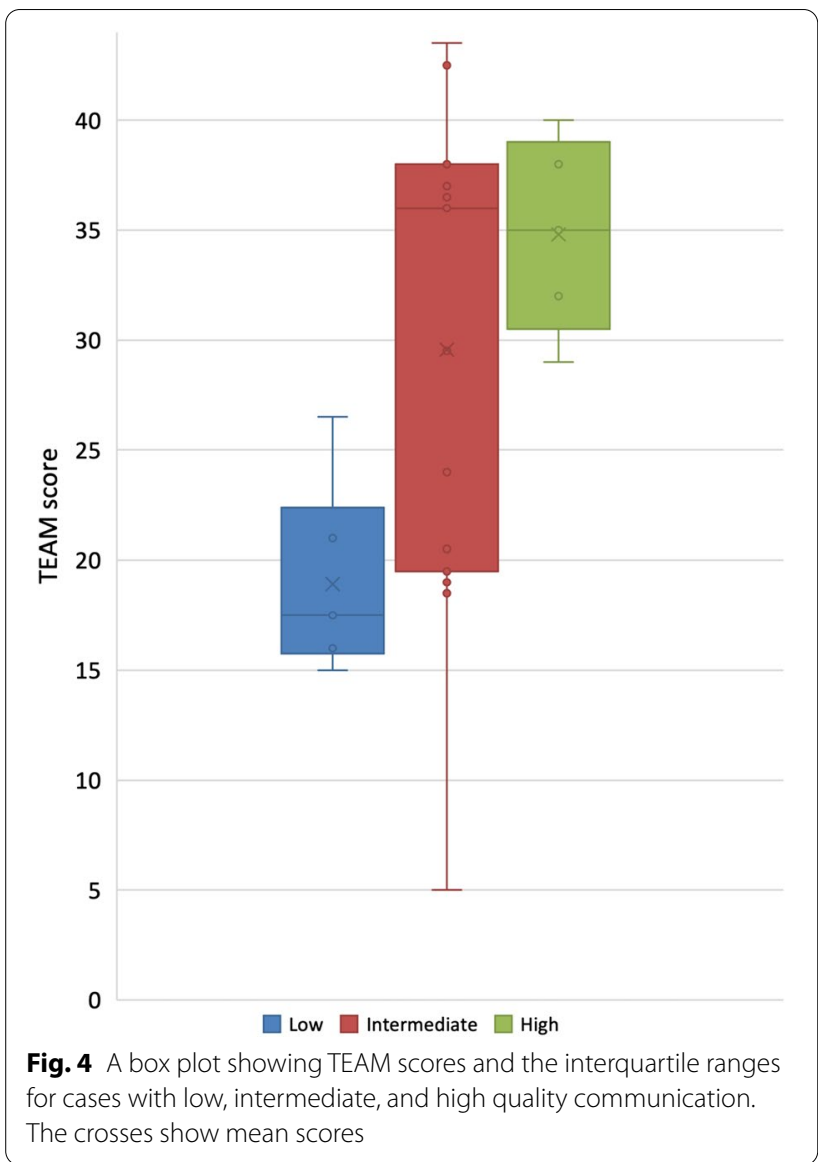

the TEAM results of the cases having low, intermediate and high quality communication. As illustrated by the box plots, a statistically significant association was observed between the quality of communication and TEAM scores $(p=0.019)$. The mean, median and range measures were as follows for the three levels of communication: low $(M=19, M d n=18$, range $=15-27)$, intermediate $(M=30, M d n=36$, range $=5-44)$ and high quality $(M=35, M d n=35$, range $=29-40)$. Cooper and colleagues suggest that scores of 33 or less are a 'poor' performance, 34-39 a 'good' team performance, and 40 and above equates to 'excellent' team performance (score range 0-44) [37]. On an item level, the Kruskal-Wallis test showed that the quality of the teams' communication was significantly associated with seven of the twelve TEAM items, cf. Table 1. Items 1-4 and 10-12 all showed significant associations between the quality of communication and the TEAM items.

\section{Discussion}

The TEAM tool has previously been shown to be a valid, reliable and feasible nontechnical observational tool for the assessment of resuscitation team performance in simulated environments and further evaluation especially in'real' settings have been called for [28, 35]. Most existing tools available for assessing teamwork performance of teams in crisis situations have been investigated using simulated scenarios and it is therefore unclear whether the measurement properties of the tools are applicable for teamwork assessment in clinical practice [25]. This study contributes with findings from studies of a Swedish version of TEAM in two emergency room settings.

The TEAM instrument was translated and adapted to a Swedish health care context. The pairwise translations occasionally generated divergent wordings and phrases but most of these were rather easily resolved by consensus. Translation-and especially when doing pairwise translations as in this study-often generates unexpected findings due to the vagueness of language or because languages are not semantically aligned [38]. Lexical correspondences do not always exist for all items and it is an essential part of translation to establish them [39]. The translation of one item turned out to be challenging as it resulted in tension between a literal translation and obtaining conceptual equivalence regarding team leadership in the two languages. A balance needed to be found between the goals of strictly following the original version and finding a wording that users in the target context were comfortable with. Translation of instruments sometimes requires altering, adding or even deleting items [40]. Such alterations were avoided by instead adding a prompt that supported interpretation of the item in the intended way and which enabled retaining a literal translation of that item itself. This solution could be a convenient option also in the translation of other instruments across languages and cultures.

This study shows that the Swedish version has similar psychometric properties as the previously validated original version developed in English in 2010 confirming that the translation did not alter the properties of the instrument [35, 37]. One component was identified corresponding to the single factor, 'teamwork', found in the original. The findings show that internal consistency and inter-rater reliability of the Swedish version also are consistent with the original. Internal consistency was excellent and inter-item correlations and itemscale analyses were high. The inter-rater reliability of the global TEAM score was also good with individual items ranging between fair and excellent with most items getting either good or excellent results. Ceiling effects were observed and a reason for this may be that the participating teams were well above average when it comes to both 
competence and experience. The observed teams were teams managing high-priority cases at two of the largest emergency departments in Sweden and even though much variation was observed between cases-all scale values were used with only one exception - their (high) levels of teamwork experience are likely to have generated the disproportionately high scores. Future studies should evaluate the instrument using teams with more varying levels of experience.

Validity was supported by the observation that the Swedish TEAM instrument discriminated between cases of low, intermediate and high quality of communication. Teams displaying clear communication had higher TEAM scores than teams with less clear communication. The communication quality was based on a count of the two key elements of closed-loop communication, the numbers of clear and unclear orders and confirmations. Closed-loop communication is a well-established communication strategy in emergency teams [41] and teams using closed-loop communication are associated with greater clinical efficiency compared to teams with less clear communication [42]. While there admittedly are many more aspects of communication and teamwork than closed-loop communication, the clear association between TEAM results and the clarity of the communication indicates construct validity. Moreover, the categorizations of the communication quality were based on real time counts of well-defined, observable behaviors rather than retrospective assessments or generalizations minimizing the need for interpretation and risks of biases. An alternative approach could have been to investigate how TEAM scores are associated with characteristics of the teams such as training, experience or team composition, but the performance of teams may vary from case to case regardless of proper training, experience or team composition and a strength of this study was that the analyses were based on the teams' actual performance in these specific cases rather than on some general characteristic.

Observing and assessing leadership, teamwork and team interaction in interprofessional teams in the emergency department is a challenging task. A limitation of this study is that the assessments were done in real-time. In many cases, if possible, it may be preferable to make assessments based on video-recordings as they can be replayed to double-check observations and even scrutinized in slow-motion. Recordings could also enable other types of analyses with other observers. A video-recording also ensures that observers see the same thing which is not possible when performing direct observation. The observers in our study often stood in different ends of the room giving them different views of the teams and events possibly affecting what they observed visually and what they heard. Despite these challenges, inter-rater reliability was good implying that the TEAM instrument is robust enough also for real-time observations. For logistical reasons the same pair of observers could not perform all observations at one of the hospitals which was not optimal and this may have affected the results negatively. The presence of observers in the emergency room could potentially have affected the behaviors of the team members. However, observers (e.g., students) are not uncommon in the emergency room and studies have indicated that the effects of an observer's presence may be less of threat to validity than commonly imagined [43, 44]. Observer presence effects may be lessened when the researcher is more or less a member of the community being observed [45] and this was one reason for involving personnel from the investigated emergency departments as observers in this study. Furthermore, this study was limited to the emergency department context and it would be valuable to evaluate the TEAM instrument also in other settings and, as mentioned above, with teams who are likely to have more varying levels of experience and competence.

\section{Conclusion}

Analyzing the complexities of teamwork may be overwhelming and time-intensive and validated instruments can provide the structure that observers need for discriminating between performance levels and measuring progress. The Swedish version of the TEAM instrument was evaluated at two emergency departments which showed that it offers a reliable and valid tool for measuring teamwork. The evaluation was based on real-time observations of authentic emergency teams indicating that TEAM can contribute with a useful tool for investigating teamwork in clinical settings.

\section{Acknowledgements}

The authors would like to thank all participating teams at the Södersjukhuset and Saint Göran hospitals as well as all observers, translators, expert committee reviews members, and colleagues for their contributions and inspiring discussions during the development of this instrument. We thank Professor Sari Ponzer, M.D. and Professor Italo Masiello for encouragement and making this project happen. Special thanks go to Erik Borgström, M.D., Professor Jussi Karlgren, Silja Karlgren, M.D., and Professor Lisa Kurland, M.D., for important contributions to the translations.

\section{Authors' information}

KK is an Associate Professor in medical education at the Södersjukhuset hospital and Karolinska Institutet in Stockholm, Sweden, and at the Western Norway University of Applied Sciences, in Bergen, Norway. His research interests include technology-enhanced learning and simulation and his recent work has focused on debriefing, teamwork and trauma management training. $\mathrm{AD}$ is a pediatrician and consultant in neonatology. He has been involved in simulation-based team training of interprofessional health care teams since 1998 and is a co-founder of the CEPS approach to simulation and debriefing (Concept for Patient Simulation) which was originally used for neonatal resuscitation training and which today is used in different medical areas at over 30 hospitals in Sweden. AB is a RN and CRNA with long experience from military service, the emergency department and anesthesia. $A B$ also teaches TNCC, AMLS and CEPS. ADN is a clinical nurse specialist in emergency care and 
care unit manager at the emergency department of Södersjukhuset where she is involved in educating through simulation-based, interprofessional team training. GF is a RN with an interest in team training and simulation and has been involved in team training at Södersjukhuset for many years and currently works at Södertälje sjukhus. MAF is a Biostatistician at Karolinska Institutet in Stockholm. His research interests are mainly modeling and epidemiology of infectious diseases. SC is a Healthcare Professor working at Federation University Australia. Formerly from the UK, his PhD studies included the observation of resuscitation team with the ultimate development of the TEAM. His research interests include non-technical skills, patient safety, education and simulation approaches. TL is a clinical nurse specialist (A\&E) at Capio St. Göran's Hospital. Combined with his clinical practice he is also a senior project manager in health care systems. His major work contributions lie in emergency care models, team training, triage and ER and disaster simulation training. CP is a care unit manager and a clinical nurse specialist (A\&E) at Capio St. Göran's Hospital. Her main field of work andspecialty is leadership and coaching skills, emergency staffing and managing, team training and adult learning in emergency medicine.

\section{Authors' contributions}

$K K, A D$, and CP planned and designed the study. KK led the translation process which was coordinated with SC. KK, AD, CP, GF, AB, and SC contributed to translations and/or the translation reviews. GF, ADN, and $A B$ performed the data collection at the Södersjukhuset hospital while CP and TL did the same at the Saint Göran hospital. MAF and KK performed the statistical analyses. KK wrote the first version of the manuscript and all authors read, contributed to, and approved the final manuscript.

\section{Funding}

Open access funding provided by Karolinska Institute. This work was supported by the regional agreement on medical training and clinical research (ALF) between Stockholm County Council and Karolinska Institutet, and by the Research, Education, and Development funds at Södersjukhuset.

\section{Availability of data and materials}

The datasets analyzed during the current study are available from the corresponding author on reasonable request.

\section{Declarations}

\section{Ethics approval and consent to participate}

Ethics approval was obtained from the regional ethical review authority in Stockholm (reference number 2016/2102-31/5). All personnel at the emergency departments were informed about the study in advance. They were informed that the aim of the study was not to assess individuals, that names or other data identifying individuals would not be collected and that they had a right to call off the study at any time without having to provide an explanation.

\section{Consent for publication}

Not applicable.

\section{Competing interests}

The authors declare that they have no competing interests.

\section{Author details}

${ }^{1}$ Department of Research, Education, Development and Innovation, Södersjukhuset, 11883 Stockholm, Sweden. MINT, Department Learning, Informatics, Management and Ethics, Karolinska Institutet, 17177 Stockholm, Sweden. ${ }^{3}$ Faculty of Health and Social Sciences, Western Norway University of Applied Sciences, 5063 Bergen, Norway. ${ }^{4}$ Department of Neonatology, Sachs' Children and Youth Hospital, Stockholm, Sweden. ${ }^{5}$ Department of Emergency, 11883 Södersjukhuset, Stockholm, Sweden. ${ }^{6}$ Department of Clinical Science and Education, Södersjukhuset, Karolinska Institutet, Södersjukhuset, 11883 Stockholm, Sweden. ${ }^{7}$ Health Innovation and Transformation Centre (HITC), School of Health, Federation University Australia, Room 113, Building 1, Berwick Campus, Clyde Road, Berwick, VIC 3922, Australia. ${ }^{8}$ Department of Emergency Medicine, Capio S:t Göran's Hospital, 112 81 Stockholm, Sweden.
Received: 19 June 2021 Accepted: 8 September 2021

Published online: 20 September 2021

\section{References}

1. Kilner E, Sheppard LA. The role of teamwork and communication in the emergency department: a systematic review. Int Emerg Nurs. 2010;18:127-37.

2. Brock D, Abu-Rish E, Chiu C-R, Hammer D, Wilson S, Vorvick L, Blondon K, Schaad D, Liner D, Zierler B. Republished: interprofessional education in team communication: working together to improve patient safety. Postgrad Med J. 2013;89(1057):642-51.

3. Schmutz JB, Meier LL, Manser T. How effective is teamwork really? The relationship between teamwork and performance in healthcare teams: a systematic review and meta-analysis. BMJ Open. 2019;9(9):e028280.

4. Weller J, Frengley R, Torrie J, Shulruf B, Jolly B, Hopley L, Hendersdon K, Dzendrowskyj P, Yee B, Paul A. Evaluation of an instrument to measure teamwork in multidisciplinary critical care teams. BMJ Qual Saf. 2011. https://doi.org/10.1136/bmjqs.2010.041913.

5. Kohn LT, Corrigan JM, Donaldson MS. To err is human: building a safer health system. Washington: National Academy Press; 2000.

6. Lingard L, Espin S, Whyte S, Regehr G, Baker GR, Reznick R, Bohnen J, Orser B, Doran D, Grober E. Communication failures in the operating room: an observational classification of recurrent types and effects. BMJ Qual Saf. 2004;13(5):330-4.

7. Eisenberg EM, Murphy AG, Sutcliffe K, Wears R, Schenkel S, Perry S, Vanderhoef M. Communication in emergency medicine: implications for patient safety. Commun Monogr. 2005;72(4):390-413.

8. Weaver SJ, Lyons R, DiazGranados D, Rosen MA, Salas E, Oglesby J, Augenstein JS, Birnbach DJ, Robinson D, King HB. The anatomy of health care team training and the state of practice: a critical review. Acad Med. 2010;85(11):1746-60. https://doi.org/10.1097/ACM.0b013e3181f2e907.

9. Salas E, DiazGranados D, Weaver SJ, King H. Does team training work? Principles for health care. Acad Emerg Med. 2008;15(11):1002-9. https:// doi.org/10.1111/j.1553-2712.2008.00254.x.

10. Karlgren K, Paavola S, Ligorio MB. Introduction: what are knowledge work practices in education? How can we study and promote them? Res Pap Educ. 2020;35(1):1-7. https://doi.org/10.1080/02671522.2019.1677761.

11. Karlgren $K$, Lakkala M, Toom A, Ilomäki L, Lahti-Nuuttila P, Muukkonen $H$. Assessing the learning of knowledge work competence in higher education-cross-cultural translation and adaptation of the Collaborative Knowledge Practices Questionnaire. Res Pap Educ. 2020;35(1):8-22.

12. Muukkonen H, Lakkala M, Lahti-Nuuttila P, Ilomäki L, Karlgren K, Toom A. Assessing the development of collaborative knowledge work competence: scales for higher education course contexts. Scand J Educ Res. 2020;64(7):1071-89.

13. Larsson F, Borgström E, Luthander CM, Dahlström A. Träna på teamarbete för säker förlossningsvård! Läkartidningen. 2015;112(27-28):1204-5.

14. Sonesson L, Boffard K, Lundberg L, Rydmark M, Karlgren K. The challenges of military medical education and training for physicians and nurses in the Nordic countries - an interview study. Scand J Trauma Resusc Emerg Med. 2017;25(1):1-10. https://doi.org/10.1186/s13049-017-0376-y.

15. Hommel A, Lindgren S. Inför teamarbete i vårdutbildningarna. Dagens Samhålle 2017 June 28th; 14. https://www.dagenssamhalle.se/chefoch-arbetsgivare/arbetsvillkor/infor-teamarbete-i-vardutbildningarna/. Accessed 18 April 2021.

16. Pukk Härenstam K, Lindgren P. Teamarbete präglar sjukvården allt mer. Att kommunicera och arbeta i team kräver övning - utmaning omvandla träning till klinisk vardag. Lakartidningen. 2016;113:D7CP.

17. Hohenhaus SM, Powell S, Haskins R. A practical approach to observation of the emergency care setting. J Emerg Nurs. 2008;34(2):142-4.

18. Harvey SA. Observe before you leap: why observation provides critical insights for formative research and intervention design that you'll never get from focus groups, interviews, or KAP surveys. Glob Health Sci Pract. 2018;6(2):299-316.

19. Karlgren K, Larsson F, Dahlström A. Eye-opening facilitator behaviours: an interaction analysis of facilitator behaviours that advance debriefings. BMJ Simul Technol Enhanc Learn. 2020;6(4):220-8. https://doi.org/10. 1136/bmjstel-2018-000374. 
20. Allvin R, Berndtzon M, Carlzon L, Edelbring S, Hult H, Hultin M, Karlgren K, Masiello I, Källestedt MLS, Tamás É. Confident but not theoretically grounded - experienced simulation educators' perception of their own professional development. Adv Med Educ Pract. 2017;8:99-108. https:// doi.org/10.2147/AMEP.S123517.

21. Rosen MA, Salas E, Wilson KA, King HB, Salisbury M, Augenstein JS, Robinson DW, Birnbach DJ. Measuring team performance in simulationbased training: adopting best practices for healthcare. Soc Simul Healthc. 2008;3(1):33-41.

22. Manser T. Teamwork and patient safety in dynamic domains of healthcare: a review of the literature. Acta Anaesthesiol Scand. 2009;53(2):143-51.

23. Cooper S, Endacott R, Cant R. Measuring non-technical skills in medical emergency care: a review of assessment measures. Open Access Emerg Med. 2010;2:7-16.

24. Sevdalis N, Hull L, Birnbach D. Improving patient safety in the operating theatre and perioperative care: obstacles, interventions, and priorities for accelerating progress. Br J Anaesth. 2012;109(suppl_1):i3-16.

25. Boet S, Etherington N, Larrigan S, Yin L, Khan H, Sullivan K, Jung JJ, Grantcharov TP. Measuring the teamwork performance of teams in crisis situations: a systematic review of assessment tools and their measurement properties. BMJ Qual Saf. 2019;28(4):327-37.

26. Sevdalis N. Non-technical skills and the future of teamwork in healthcare settings. The imperial centre for patient safety and service quality, 2013.

27. Kinnunen $\mathrm{K}$, Laks J. TEAM-mittari yhtenäistää simulaatioiden arviointia ja kehittämistä. Spirium. 2019;54(4):30-3.

28. Maignan M, Koch F-X, Chaix J, Phellouzat P, Binauld G, Muret RC, Cooper SJ, Labarère J, Danel V, Viglino D. Team emergency assessment measure (TEAM) for the assessment of non-technical skills during resuscitation: validation of the French version. Resuscitation. 2016;101:115-20.

29. Freytag J, Stroben F, Hautz WE, Schauber SK, Kämmer JE. Rating the quality of teamwork - a comparison of novice and expert ratings using the Team Emergency Assessment Measure (TEAM) in simulated emergencies. Scand J Trauma Resusc Emerg Med. 2019;27(1):1-8.

30. Beaton D, Bombardier C, Guillemin F, Ferraz MB. Recommendations for the Cross-Cultural Adaptation of the DASH \& QuickDASH Outcome Measures. 2007. http://dash.iwh.on.ca/sites/dash/files/downloads/cross_ cultural_adaptation_2007.pdf. Accessed 3 Feb 2019.

31. Borsa JC, Damásio BF, Bandeira DR. Cross-cultural adaptation and validation of psychological instruments: some considerations. Paidéia. 2012;22(53):423-32. https://doi.org/10.1590/1982-43272253201314.

32. Tsang S, Royse CF, Terkawi AS. Guidelines for developing, translating, and validating a questionnaire in perioperative and pain medicine. Saudi J Anaesth. 2017;11(Suppl 1):S80.

33. Guillemin F, Bombardier C, Beaton D. Cross-cultural adaptation of health-related quality of life measures: literature review and proposed guidelines. J Clin Epidemiol. 1993;46(12):1417-32.

34. Eremenco SL, Cella D, Arnold BJ. A comprehensive method for the translation and cross-cultural validation of health status questionnaires. Eval Health Prof. 2005;28(2):212-32.
35. Cooper S, Cant R, Porter J, Sellick K, Somers G, Kinsman L, Nestel D. Rating medical emergency teamwork performance: development of the Team Emergency Assessment Measure (TEAM). Resuscitation. 2010;81(4):446-52.

36. Cicchetti D. Guidelines, criteria, and rules of thumb for evaluating normed and standardized assessment instruments in psychology. Psychol Assess. 1994;6(4):284-90.

37. Cooper S, Cant R, Connell C, Sims L, Porter JE, Symmons M, Nestel D, Liaw SY. Measuring teamwork performance: validity testing of the Team Emergency Assessment Measure (TEAM) with clinical resuscitation teams. Resuscitation. 2016;101:97-101.

38. Thompson B, Roberts S, Lupyan G. Quantifying semantic alignment across languages. In: Paper presented at the Research presented at the 40th annual meeting of the Cognitive Science Society, Madison, Wl; 2018.

39. Karlgren H, Karlgren J, Nordström M, Pettersson P, Wahrolen B. Dilemma — an instant lexicographer. In: Paper presented at the COLING the 15th international conference on computational linguistics, Aug 5-9; Kyoto, Japan; 1994.

40. van Widenfelt BM, Treffers PDA, de Beurs E, Siebelink BM, Koudijs E. Translation and cross-cultural adaptation of assessment instruments used in psychological research with children and families. Clin Child Fam Psychol Rev. 2005;8(2):135-47. https://doi.org/10.1007/s10567-005-4752-1.

41. Jacobsson M, Hargestam M, Hultin M, Brulin C. Flexible knowledge repertoires: communication by leaders in trauma teams. Scand J Trauma Resusc Emerg Med. 2012;20(1):1-9.

42. Siassakos D, Bristowe K, Draycott T, Angouri J, Hambly H, Winter C, Crofts J, Hunt L, Fox R. Clinical efficiency in a simulated emergency and relationship to team behaviours: a multisite cross-sectional study. BJOG. 2011;118(5):596-607.

43. Schnelle JF, Ouslander JG, Simmons SF. Direct observations of nursing home care quality: does care change when observed? J Am Med Dir Assoc. 2006;7(9):541-4.

44. Harvey SA, Olórtegui MP, Leontsini E, Winch PJ. "They'll change what they're doing if they know that you're watching": measuring reactivity in health behavior because of an observer's presence-a case from the Peruvian Amazon. Field Methods. 2009;21 (1):3-25.

45. Hames R, Paolisso M. Behavioral observation. In: Bernard HR, Gravlee CC, eds. Handbook of methods in cultural anthropology. 2nd ed. Lanham, Maryland: Rowman \& Littlefield, 2014. p. 293-312.

\section{Publisher's Note}

Springer Nature remains neutral with regard to jurisdictional claims in published maps and institutional affiliations.

Ready to submit your research? Choose BMC and benefit from:

- fast, convenient online submission

- thorough peer review by experienced researchers in your field

- rapid publication on acceptance

- support for research data, including large and complex data types

- gold Open Access which fosters wider collaboration and increased citations

- maximum visibility for your research: over 100M website views per year

At BMC, research is always in progress.

Learn more biomedcentral.com/submissions 